\title{
Corporate strategy and information disclosure
}

\author{
Daniel Ferreira* \\ and
}

Marcelo Rezende**

We examine voluntary disclosures of information about corporate strategies. We develop a model in which managers choose whether to reveal their strategic plans only to some partners of the firm or also to the outside world. We show that managers face a tradeoff when deciding whether to disclose their private information to outsiders. On the one hand, by disclosing their intentions, managers become reluctant to change their minds in the future. This may lead them to make inefficient project implementation decisions. On the other hand, information disclosure about corporate strategy provides strong incentives for partners of the firm to undertake strategy-specific investments.

\section{Introduction}

Voluntary disclosure of information by corporations is widespread. For example, much of the information provided by firms in their annual reports is not required by laws or specific regulations (Botosan, 1997). Other than through annual reports, a firm's management may also make its private information available to outsiders through press releases, conference calls, Internet sites, and mission statements, among others. Managers who disclose information through these sources reach audiences far beyond the boundaries of their firms.

In this article, we provide a theory to explain the voluntary disclosure of information concerning the strategic decisions within a firm. As a practical concern, investors and other constituencies do appear to care about the disclosure of information regarding corporate strategy. For example, in a recent study on transparency and disclosure around the world, Standard \& Poor's examined company annual reports for many different categories of information, many of them directly related to strategic decisions. Some of the questions included by S\&P's researchers were: "Is

* London School of Economics and Political Science, CEPR and ECGI; d.ferreira@1se.ac.uk.

** Board of Governors of the Federal Reserve System; marcelo.rezende@ frb.gov.

We thank two anonymous referees, Raymond Deneckere (Editor), Renée Adams, Mauricio Bugarin, Mike Burkart, Wouter Dessein, Luis Garicano, Mariassunta Giannetti, Lars Stole, Eric Van den Steen and seminar participants at the Getulio Vargas Foundation, Stockholm School of Economics, University of São Paulo, the 2003 North American Summer Meeting of the Econometric Society (Evanston, Ill.), the 2004 International Industrial Organization Conference (Chicago, Ill.) and the 2004 Annual Congress of the European Economic Association (Madrid) for comments. The views expressed herein are our own and do not necessarily reflect those of the Board of Governors or the staff of the Federal Reserve System. 
there a discussion of corporate strategy? (Does the company) report the details of the kind of business it is in? Does the company disclose its plans for investment in the coming years?" (Patel and Dallas, 2002). These questions highlight the fact that information about strategy very often reflects managerial intentions, i.e., information about what a firm's management has in mind for the future of its company. This fact, however, remains relatively unaddressed by theorists.

In our model, the most important information asymmetry is between a partner of the firm (employee, supplier, strategic partner, or any other stakeholder) and managers. This general partner may choose to undertake some strategy-specific investments. For example, workers may try to come up with new ideas that can only be implemented if the firm does not change its scope. By releasing information about their future plans for the firm, managers provide firm's partners with information that is valuable in assessing the profitability of such investments.

We identify four main characteristics of information about managerial intentions that are important for our analysis:

(i) Information about managerial intentions tends to be "soft;" that is, it is information that cannot be directly verified. For example, when managers report that they are planning to enter a given line of business, this information cannot be verified before the firm actually implements this plan. Thus, the softness of the information about managerial intentions raises the question of its credibility.

(ii) Information about managerial intentions is very often forward looking. Therefore, when credible, disclosures of information about strategy may have important effects on the incentives of partners to undertake long-run, firm-specific investments.

(iii) Managers' intentions are formed based on managers' own private information. If moretalented managers have better information, the market for executives (e.g., headhunters) may use the disclosure of managerial intentions to update its beliefs about a manager's ability.

(iv) Given the informal nature of information about managerial intentions, managers may opt to announce their plans only to some partners of the firm or to the outside world as well (public announcements). For example, Cools and van Praag (2003) provide evidence that not all firms that announce corporate targets internally also disclose that information to outsiders.

With these characteristics in mind, we then ask four main questions: What motivates managers to disclose information about strategy? What makes managerial disclosures credible? Is voluntary disclosure of information about strategy value enhancing? Finally, when should we expect to see voluntary disclosures of information about corporate strategy?

We investigate these questions in a model where a manager wants to induce a partner of the firm to undertake some strategy-specific investments. Such investments are not contractible; thus, the partner's payoff may depend on the implementation of a specific strategy by the manager. If public disclosure of information somehow commits managers not to change strategic directions, a firm's partners will be more likely to undertake investments that are related to these strategies. We show that managers' announcements are credible when they are public, i.e., when everyone can see them.

The logic behind this result is as follows. In our setup, the main decision the manager has to make is whether she should release her information only to the partners (internal announcements) or to the outside world as well (public announcements). Managers would like to maximize firm value as long as they have some stake in it. However, they may differ in their abilities to forecast the future. Good managers are the ones who have more precise information. If a manager suggests a given strategic direction for the firm and later decides to change it, she signals to the market that her initial information was not very precise. Therefore, the managerial labor market provides managers with incentives to stick to their original plans, even when changing directions is the optimal thing to do from the shareholders' standpoint. This effect makes public announcements 
credible because managers will be reluctant to make changes that are not consistent with their original statements.

Our model thus highlights the fact that managers face a tradeoff when deciding whether to disclose their private information to outsiders. On the one hand, the commitment to the proposed strategy that is achieved when there is disclosure provides strong incentives for partners of the firm to undertake strategy-specific investments. On the other hand, by disclosing their intentions, managers will be reluctant to change their minds in the future, and this reluctance may lead them to make inefficient project implementation decisions.

There are many reasons why managers might want to publicly disclose the firm's strategy, such as reducing uncertainties or influencing investors in general. Thus, managers should weigh the costs and benefits of strategy disclosure highlighted in this article against other costs and benefits of disclosure targeted at investors. Similarly, disclosure of financial and accounting information may also reveal information about corporate strategy as a by-product. Thus, the effects we highlight here are also important for decisions to disclose information in general, as long as information disclosure reveals something about strategy.

Most previous works have focused on financial disclosure rather than corporate strategy disclosure. Although we were unable to find any theoretical analysis of this topic, there are a few research articles that analyze the empirical relevance of disclosure of nonfinancial and qualitative information. Amir and Lev (1996) find that the disclosure of nonfinancial information, such as market growth and market penetration, increases value in the wireless communications industry. Narayanan et al. (2000) provide evidence that the voluntary disclosure of qualitative information about managerial intentions in R\&D project announcements affects firm policies and outcomes.

Moreover, most theoretical articles on disclosure have focused on communication between managers and investors (e.g., Diamond, 1985; Diamond and Verrecchia, 1991; Stocken, 2000; Boot and Thakor, 2001). Information disclosed to investors of publicly listed firms is a nonrival good, thus other stakeholders may also be interested in it. This gap in the literature is acknowledged by Healy and Palepu (2001, p. 406): “Corporate disclosure can also be directed to stakeholders other than investors. However, there has been relatively little research on these types of voluntary disclosures."

Our work is also related to a recent economic literature on managerial vision (Rotemberg and Saloner, 2000; Hart and Holmström, 2002; Van den Steen, 2005). These articles characterize a manager's vision as a bias toward particular activities. This literature gives a behavioral interpretation for managerial biases: they arise either from differences in preferences or from differences in opinions. Furthermore, these biases are assumed to be common knowledge. When managers' visions imply that they will commit themselves to always implement innovations in certain activities, workers will put more effort into developing ideas that are related to these activities. In short, vision is a partial commitment device by which managers can convince workers to exert effort. In this article, we adopt a different approach. We assume that managerial intentions are private information; thus, the manager is not committed to her announced plans. In this case, we show that public disclosure of information is a means of achieving commitment.

Many articles model the behavior of managers in settings in which there is asymmetric information. In these models, managers take different sorts of inefficient actions in order to manipulate information: managers may behave in a stubborn manner (Kanodia, Bushman, and Dickhaut, 1989; Boot, 1992), they may act too conservatively or too aggressively (Zwiebel, 1995; Prendergast and Stole, 1996), they may mimic the behavior of others (Scharfstein and Stein, 1990) or they may conform to the market expectations of their choices (Brandenburger and Polak, 1996). Similar to these previous works, our model has an element of conformism-managers will conform to their previously stated views. Unlike them, however, the manager in our model uses her own conformist behavior to provide incentives to firm's partners. Thus, managerial conformism in our analysis has both costs and benefits.

The structure of the article is as follows. We provide an informal discussion of the model in Section 2. We present our model in Section 3 and analyze its robustness to different assumptions 
concerning the compensation of managers in Section 4. In Section 5, we discuss some empirical implications and in Section 6 we make our final remarks.

\section{Informal description of the model}

Before we describe the model, we first provide an informal discussion of its main elements. We model the behavior of a top manager who is responsible for the main decisions in a given firm (e.g., the CEO). The manager has some stake in the firm; therefore, she would like to choose actions that maximize firm value whenever these actions are not too costly. We abstain from issues related to the design of incentive contracts for the manager in order to focus only on the essentials. An extension of the model in which shareholders (or the board) choose an optimal managerial compensation scheme is straightforward, but it is omitted here for the sake of brevity.

The type of decisions we have in mind are broadly defined as the firm's "strategy," such as the choice of which product lines the firm will develop. In order to fix ideas, let us consider the case of a manager who has to decide whether or not to implement some innovation. Innovations (or ideas) are generated by workers (who play the part of the firm's partner in this case), who have to exert some effort in order to increase the probability that a profitable idea will materialize. A crucial assumption is that the workers' effort is not contractible. As in Rotemberg and Saloner (2000), we assume that workers are compensated only when they come up with new ideas and the manager decides to implement them.

An idea can yield a positive return only if it is consistent with the firm's directions. Thus, it is important for workers to have knowledge about the firm's future directions because this affects the probability that their ideas will be implemented. The manager may try to convey this information; she may tell the workers what her vision for the future of the firm is (see, for example, Rotemberg and Saloner, 2000; Van den Steen, 2005). For example, the CEO may tell the workers that she is committed to keeping the company in business A. In our model, however, the problem with this promise is that it is not credible. The CEO has an incentive to disclose her vision because, if workers believe in it, they will exert more effort. However, after workers have exerted effort, she has no incentive to keep her promises and may think it is a good idea to change the firm's business from A to B. In a world of rational agents, workers anticipate that managerial vision is not credible and therefore do not respond to it by exerting more effort.

Credible announcements are possible, however, if managers have career concerns. Managers know that there is a probability that another job opportunity might arise and that they may be inclined to accept it. They also know that any actions they take that are visible to individuals outside the firm may signal their abilities to the market. The market for executives will pay higher salaries to better managers. Therefore, when choosing to announce their plans and when choosing the final direction for the firm, managers care not only about their effects on expected profits but also about the effects of their actions on the market's perceptions of their talent. Even if managers do not leave the firm, if they develop a reputation of being talented, they can renegotiate higher salaries with their current firm (or board of directors) because their outside options have improved.

However, there is also an incentive for managers to conceal their information from the market. If the market does not know the manager's information, it cannot use it to infer anything about the manager's skills. Therefore, we allow the manager in our model to choose whether to disclose her plans only internally (to her workers only) or to the outside world as well (public announcements). When announcements are public, they are also credible. Knowing that, managers may choose to disclose their views to the market in order to induce a firm's partners to undertake valuable strategy-specific investments.

\section{Model}

Setup. There are two main strategic directions (activities) the firm can choose: $A$ or $B .^{1}$ Strategies are mutually exclusive. There is uncertainty regarding which of the two strategies yields

${ }^{1}$ Here we use the word "strategy" in its usual business meaning. Later, we will also use the term "strategy" in its game-theoretic sense.

(C) RAND 2007. 


\section{FIGURE 1}

TIMELINE

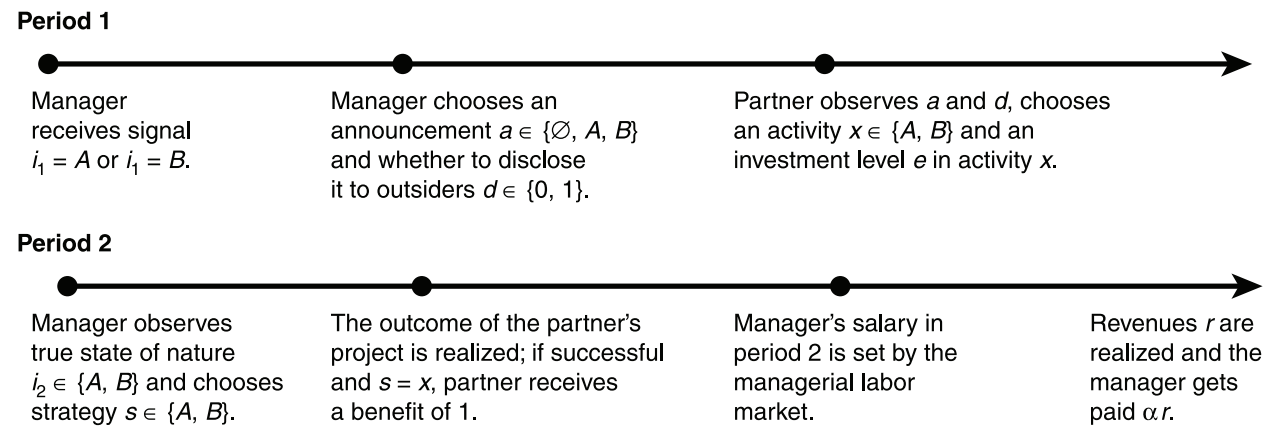

higher profits. We assume that $A$ and $B$ are equally likely to be the best strategy, from an ex ante standpoint. The revenue from adopting the good strategy is $R$ and the revenue from adopting the bad one is zero.

The firm is run by a risk-neutral manager (she) who derives utility only from money $m$. The manager is entitled to a fixed fraction $\alpha$ of the profits and is also paid a fixed salary $w$. For simplicity, we take $\alpha$ as exogenous; an extension of the model in which shareholders choose an optimal $\alpha$ is straightforward. There is one expected utility maximizing partner (he); an employee, supplier, strategic partner, or any other stakeholder with utility $m-e$, where $m$ is money and $e \in[0,1]$ is both the level and the cost of his investment (this can be interpreted as effort if the partner is a worker).

There are two types of managers: $H$ and $L$ (high and low ability). The proportion of $H$ in the population is $\pi$. No one has private information on types, not even the manager herself.

There are two periods, and the timing of actions within each period is described below. See also Figure 1.

Period 1. In period 1, the firm chooses a manager from the population randomly. The manager then receives a signal, $i_{1} \in\{A, B\}$, which is private information. It equals the good strategy with probabilities

$$
p_{H}=1 \quad \text { and } \quad p_{L} \in[1 / 2,1),
$$

that is, type- $H$ managers receive more precise signals. Managerial ability is characterized in a similar way in Scharfstein and Stein (1990) and Prendergast and Stole (1996).

For notational simplicity, we define the ex ante probability of receiving the correct signal by

$$
p=\pi+(1-\pi) p_{L} .
$$

The manager can choose to costlessly communicate a message $a \in\{\emptyset, A, B\}$ to the partner. We call $a$ her announcement. Announcements are observable but not verifiable; thus, contracts written on $a$ cannot be enforced in courts. The interpretation is that $a$ is the activity that she claims is going to be the one chosen by the firm (either $A$ or $B$ ). She has a choice of not disclosing her information, in which case we say that $a=\emptyset$.

We assume that the manager may choose to disclose her information only to the partner or also to the market. Formally, she chooses $d \in\{0,1\}$, where $d=1$ if the manager allows the market to observe her message $a$ and $d=0$ otherwise. Thus, $d=1$ if managers make public announcements. We assume that the manager cannot send conflicting messages, such as saying $A$ to partners and $B$ to outsiders. Had we alternatively allowed for conflicting messages, as long as partners can also observe public announcements, managers would never choose to send conflicting messages in equilibrium. This is consistent with the empirical evidence in Cools and van Praag (2003), who find that "by assessing the correspondence between externally communicated targets and targets 
that are actually used within the company we can conclude that virtually none of the disclosed quantified targets are in conflict with internally communicated targets" (p. 16).

The disclosure decision $d$ is, in principle, verifiable; thus, shareholders might include it in contracts with managers if they wish. However, we will show that, under our assumptions, this is unnecessary. In equilibrium, managers voluntarily choose to disclose their business strategy information to outsiders if and only if these disclosures are value enhancing. Thus, shareholders will never have to pay managers for information disclosure.

After observing $a$ and $d$, the partner chooses an activity $x \in\{A, B\}$ for which he will make a specific investment. The partner chooses an unobservable level of investment (or effort) $e$ in the chosen activity $x$. For simplicity, we denote by $e$ both the cost and the level of this investment, and we also assume that they are the same in either $A$ or $B$.

The more the partner invests in a project, the higher the probability that it is successful, in which case he receives an exogenously given benefit that we normalize to 1 . If he does not invest in a project or if the project is not successful, he receives no benefits. We assume that no other contract between the manager and the partner is possible and that the partner's participation constraint is always satisfied. ${ }^{2}$

Period 2. At the beginning of period 2, the manager privately observes the true state of nature $i_{2} \in\{A, B\}$. Immediately after observing it, the manager has to make an irreversible choice of strategy $s \in\{A, B\}$. The choice of strategy is observable to everyone but is not verifiable. ${ }^{3}$ She then observes whether or not the investment made by the partner in activity $x \in\{A, B\}$ was successful. For notational purposes, we say that $S=1$ if the investment is successful and $S=0$ if not. The probability of the partner's project being successful is an increasing function of his investment $q(e):[0,1] \rightarrow[0,1]$. We assume $q^{\prime}(e)>0, q^{\prime \prime}(e)<0, q^{\prime}(0)>1, q^{\prime}(1)<1$. Success of a project is too vague a concept to be included in a contract; thus, we assume that $S$ is not verifiable. Therefore, only if the manager chooses the same activity as the partner, $s=x$, and if the partner's project is successful, the partner receives his benefit. Otherwise, the partner does not receive anything.

At this point, the salary of the manager in period 2 is set by the competitive forces of a managerial labor market. The managerial labor market places a higher value on managers of type $H$ because they are better at choosing the right strategies. Suppose the market is willing to pay $w_{H}$ for a manager of type $H$ and $w_{L}$ for a manager of type $L$. Accordingly, $w_{H}>w_{L}$. Without knowledge of $i_{1}$ and $i_{2}$, the market pays $w=\pi w_{H}+(1-\pi) w_{L}$. However, in general, the market will use its beliefs about $i_{1}$ and $i_{2}$ to Bayesian update its beliefs about the manager's type.

In order to emphasize the long-term nature of strategic planning, we assume that managers' salaries are determined before the realization of the outcomes of their chosen actions. Decisions concerning major strategic issues will have their full consequences only in the very long run; thus, it is possible that managers will not be around when the final outcome of their choices becomes known. In our model, this causes the market for executives to care only about managers' actions, which are readily observable, given the impossibility of waiting until outcomes are fully realized. We provide a more thorough discussion on the assumptions concerning the types of compensation contracts offered by the market for executives in Section 4.

Finally, the true state of nature $i_{2} \in\{A, B\}$ is revealed to everyone. Firm revenue is

$$
r= \begin{cases}R+h & \text { if } i_{2}=s=x \text { and } S=1, \\ R & \text { if } i_{2}=s=x \text { and } S=0, \\ R & \text { if } i_{2}=s \neq x, \\ 0 & \text { if } i_{2} \neq s,\end{cases}
$$

where $h>0$ can be interpreted as a measure of how valuable partners' ex ante investments are.

\footnotetext{
${ }^{2}$ It is possible to endogenize the partner's benefit and treat it as a cost to the firm. This modification slightly complicates the model and adds few additional insights.

${ }^{3}$ Although everyone understands what a given strategy is once it has been implemented, it could be extremely difficult to describe it ex ante in a formal contract.
} 
Example. In order to fix ideas, it is helpful to consider a simple numerical example before we solve our model for the general case.

Let the probability that the low-quality manager receives the correct signal be $p_{L}=1 / 2$. This is a simple case in which the low-quality manager has no informational advantage, while the high-quality manager is always fully informed. The proportion of high-quality managers in the population is $\pi=1 / 3$, implying that the ex ante probability of the manager being right is $p=2 / 3$. Let $q(e)=\sqrt{e}$.

Suppose first that the manager announces to the partner her period-1 signal, $a=i_{1}$, but cannot commit to implement the strategy $s=a$, i.e., the manager retains the option of changing her mind, in the light of the new evidence $i_{2}$ she will get in period 2, and implement $s=i_{2} \neq i_{1}$. We call this the " $d=0$ " case: the case in which announcements are only internal. In such a case, it is obvious that the partner will choose to invest in strategy $i_{1}$, but he will also take into account the probability that his investment may turn out not to be successful, if the manager decides to change strategies.

We begin by describing the behavior of the partner. The partner's optimal investment choice, $e(d=0)$, will solve

$$
\max _{e \in[0,1]} \frac{2}{3} \sqrt{e}-e
$$

implying that $e(d=0)=1 / 9$.

Let us now consider the case " $d=1$," i.e., the case of public announcements. Later, we will show formally that, in this case, commitment is sometimes possible. For now, however, let us simply assume that the manager is able to fully commit to the announced strategy $a=i_{1}$. In this case, the partner will choose his investment in order to

$$
\max _{e \in[0,1]} \sqrt{e}-e .
$$

The optimal level of investment is given by $e(d=1)=1 / 4$, which is obviously higher than the one in which there is no commitment.

We now turn to the behavior of the manager. Assuming $w_{L}=3$ and $w_{H}=6$, the salary that will be paid to the manager in a pooling equilibrium (i.e., in an equilibrium in which the market is unable to separate types) is

$$
w=\left(\frac{1}{3}\right) \times 6+\left(\frac{2}{3}\right) \times 3=4
$$

A pooling equilibrium will occur if and only if a manager who observes $i_{2} \neq i_{1}$ chooses $s=i_{1}$, i.e., the manager will stick to her announced strategy even if the information she receives in period 2 contradicts her previous information. That a pooling equilibrium has to occur in such a case is immediate: from the observation of the strategy choice $s=i_{1}$, the market is unable to distinguish between a manager who got it right $\left(i_{1}=i_{2}\right)$ and a manager who got it wrong $\left(i_{1} \neq i_{2}\right)$.

The question now is this: Will the manager stick to her announcement $s=a$ even when $i_{2} \neq i_{1}$ ? Assume that $R=10$ and that the manager holds $5 \%$ of the shares $(\alpha=0.05)$. If the manager chooses the right strategy, $s=i_{2}$, when $i_{2} \neq i_{1}$, she secures firm revenues of $R=10$, and through her shares she receives benefits $(0.05) \times 10=0.5$. On the other hand, she will reveal her type to the market, which will learn that she is of the low type and will pay her a salary of 3. Thus, the manager's utility from breaking the promise is $0.5+3=3.5$. If the manager holds on to her promise and chooses $s=a$ when $i_{2} \neq i_{1}$, firm revenues are zero. On the other hand, the market will not be able to separate types in equilibrium and will pay the manager a salary of 4 .

Thus, given our assumptions, the manager is better off if she sticks to her promise and chooses $s=a$ when $i_{2} \neq i_{1}$. Of course, this is only possible when announcements are public, so that the market can observe both $a$ and $s$. If the market can observe only $s$ but not $a$, pooling equilibria will always occur independently of what the manager does when she sees $i_{2} \neq i_{1}$. Thus, 
we have proven that publicly disclosing the announcement (the $d=1$ case) indeed makes the announcement credible.

We can now consider the disclosure decision. In period 1 , if she chooses to disclose her announcement, the manager expects to get

$$
V(d=1)=(0.05) \times\left(\frac{2}{3} 10+\frac{1}{6} h\right)+4
$$

while if she chooses to make only an internal announcement, she expects to get

$$
V(d=0)=(0.05) \times\left(10+\frac{2}{27} h\right)+4 .
$$

Thus, the manager will choose to publicly disclose her views and thus commit to a given strategy if and only if

$$
h \geq 36 \text {. }
$$

Thus, as long as the ex post value for the firm of the partner's investment is large enough, it pays for the manager to make a public announcement and commit herself.

This example illustrates the main insights behind our model. First, commitment to a strategy is good because it increases the investment of the firm's partner. Second, commitment can only be achieved when announcements are public. Third, the possibility of a pooling equilibrium in the managerial labor market is a necessary condition for public announcements to be credible. Fourth, the manager can credibly commit to a strategy by publicly disclosing her views. Fifth, public announcements are more likely to occur when the ex post value of investments is high.

Of course, we chose this example in order to convey the main message. However, it is still unclear how these results can be generalized. In particular, the probabilities were carefully chosen so that the task of updating beliefs was trivial and numerical values were such that only pooling equilibria could occur. In the rest of the article, we analyze the equilibria of this model in the general case and show that the main qualitative results are unchanged. We also discuss the hidden assumptions in more detail and provide more comparative statics results.

Remarks on the main assumptions. A straightforward way to interpret the model is to think of the partner as a worker who exerts effort in a given activity in order to generate a profitable idea for the firm. This idea can then be implemented only if the firm does not change strategic directions. The benefits the worker receives if his idea is implemented may come from an explicit contract with the manager or through other noncontractual means, such as promotions, or as a result of an increase in his bargaining power with respect to the firm.

Rather than interpreting the strategy-specific investments as the development of new ideas, one could also think of a worker who acquires a combination of skills specific to the new strategy. Lazear (2003) argues that this "skill-weights" approach is a more realistic view of firm-specific human capital investment. ${ }^{4}$

However, many other interpretations for the identity of the partner who makes strategyspecific investments are possible. It can be, for example, another firm in a joint venture with the original one or a supplier. Thus, our exogenously given benefits for the firm $(h)$ and for the partner (normalized to 1) can easily be made endogenous in some of the interpretations, but we choose the current approach both for its simplicity and generality.

The assumption of no asymmetric information concerning managers' types at the beginning of the game is a standard one in the career concerns literature (see, for example, Holmström, 1999). However, this assumption is responsible for the result that managers will choose to disclose their information if and only if this disclosure is value enhancing from the shareholders' standpoint.

${ }^{4}$ We thank an anonymous referee for suggesting this intepretation. 
When the manager starts the game with better information about her own ability, this result may not hold. In such a case, it is possible that a high-ability manager would choose to disclose her information in order to induce an equilibrium in which her type is revealed, even if such a decision is not optimal from the shareholders' standpoint.

Most of our assumptions concerning the timing of the events are natural ones, except perhaps for the assumption that the strategy implementation decision, $s$, is taken before the manager learns about the success of the partner's project, $S$. In general, there would be an option value of waiting for $S$ to happen before deciding on $s$. However, our technology gets rid of this case because knowledge of $i_{2}$ is sufficient for an optimal decision concerning $s$. This reversing of the timing does not affect the equilibrium, so we choose the current approach for simplicity because then we do not have to make the strategy decisions contingent on $S$. In a world with more contractual possibilities, reversing this timing could also improve matters if the manager could commit in period 1 not to change strategies only when $S=1$. However, it is crucial for our analysis that these types of intertemporal commitments are not possible. Once these are ruled out, again, whether $s$ is chosen before or after $S$ is not important.

An important assumption is that $h$ can be enjoyed by the firm only when $s=i_{2}$ and $S=1$. A more natural assumption would have been that at least a fraction of $h$ can be gained even if $s \neq i_{2}$. This would not change much of our results, but it would make the reversal of the timing mentioned in the paragraph above nonneutral. In particular, in such a case, there would be some extra incentives for the partner to invest because he could then affect the manager's choice in period 2.5

We postpone a thorough discussion concerning the assumptions on managerial compensation until Section 4.

Equilibrium. To solve our model, we will use the concept of perfect Bayesian equilibrium, sometimes augmented by refinements to rule out clearly unreasonable equilibria.

There are two active players in this game: the manager and the partner. Shareholders are passive residual claimers. There are four possible types of managers: $\left(i_{1}, i_{2}\right) \in\{A, B\}^{2}$. The manager's pure strategies are type dependent: $\left[a\left(i_{1}\right), d\left(i_{1}\right), s\left(i_{1}, i_{2}\right)\right] \in\{\emptyset, A, B\} \times\{0,1\} \times$ $\{A, B\}$. Notice that strategies are consistent with the timing of information revelation: $a$ and $d$ can only depend on $i_{1}$, and $s$ depends on $i_{1}$ and $i_{2}$. The partner chooses both $x$ and $e$ after observing $a$ and $d$; therefore, a pure strategy for the partner is denoted by $[x(a, d), e(a, d)] \in\{A, B\} \times[0,1] .^{6}$

Let $P\left(i_{j}=\delta \mid a, d\right)$ denote the probability that the partner thinks that the signal $i_{j}, j \in\{1,2\}$, received by the manager equals $\delta \in\{A, B\}$, given that the partner has observed $(a, d)$.

In order to solve our model, we start by analyzing the behaviors of the partner and the manager in period 1, assuming a fixed degree of credibility (to be defined shortly). Then we endogenously derive the degree of credibility from the game played in period 2 and use it to analyze the manager's disclosure decision in period 1 .

The communication game. In period 1 , the manager and the partner play a simple sender-receiver communication game, as in Crawford and Sobel (1982). The manager sends a costless message $a$ to the partner, who then chooses an action $(x, e)$ that will affect the payoffs of both players. As in Crawford and Sobel (1982), this simple communication game can have many equilibria. We will consider only equilibria that are not Pareto dominated by other equilibria. Because the preferences of managers and partners are aligned with respect to $i_{1}$ (i.e., the manager wants the partner to know $\left.i_{1}\right)$, all Pareto-undominated equilibria will display full revelation of information. Among these, we choose the "truthful" equilibrium as the focal one (i.e., an equilibrium in which the manager truthfully reveals her information in period $\left.1: a\left(i_{1}\right)=i_{1}\right)$. Other fully revealing equilibria will be equivalent to this one in the sense that they will lead to the same final payoffs for both players. ${ }^{7}$

\footnotetext{
${ }^{5}$ Again, we thank an anonymous referee for suggesting this possibility.

${ }^{6}$ In what follows, equilibria will not always be in pure strategies. In particular, there will be cases in which the manager will randomize between $s=A$ and $s=B$. No other types of randomization will occur in equilibrium.

${ }^{7}$ For example, a strategy profile such as $\{a(A)=B, a(B)=A ; x(A)=B, x(B)=A\}$ is a fully revealing equilibrium for this period-1 "game."

() RAND 2007
} 
In what follows, whenever we claim that the equilibrium is unique, we mean an equilibrium that imposes truthful revelation of information in period $1 .{ }^{8}$

Partner behavior. Here we analyze the partner's choices, taking the strategy of the manager as a given. We separate the analysis into two cases. We first derive the partner's optimal choices when announcements are only internal $(d=0)$. Then we analyze the case in which the manager makes public announcements $(d=1)$.

Proposition 1. If $d=0$, the optimal strategy for the partner is

$$
\left\{x(a, d=0)=a, e(a, d=0)=e^{n}\right\},
$$

where $e^{n}$ is such that $p q^{\prime}\left(e^{n}\right)=1$.

Proof. As we have argued, the manager truthfully reveals her signal in period 1 internally, i.e., $a=i_{1}$. However, she is unable to commit herself to choose $s=i_{1}$ in period 2. ${ }^{9}$ Therefore, because in period 2 she already knows the true state of nature, she will always choose $s\left(i_{1}, i_{2}\right)=i_{2}$. Bayesian rationality implies that partner's beliefs are such that $P\left[i_{1}=a \mid a, d=0\right]=1$ and $P\left[i_{2}=a \mid a, d=0\right]=p$. It is evident that, given truthful revelation $a=i_{1}$, the partner's best choice of activity is $x(a, d=0)=a$. His choice of investment $e(a, d=0)$ will be

$$
e(a, d=0) \in \underset{e \in[0,1]}{\arg \max } p q(e)-e .
$$

Under the assumptions on the function $q$, a unique solution for this problem exists. Also, the solution is interior and therefore characterized by

$$
p q^{\prime}\left(e^{n}\right)=1
$$

where $e^{n}$ is the investment level chosen by the partner in the case in which announcements are not public (i.e., only internal). Q.E.D.

Suppose now that the manager chooses to make a public announcement $(d=1)$. We will show later that, when the manager reveals her information to the market in period 1 , she might be able to commit herself to choose $s=a$ in period 2. In order to deal with all possible cases, let us define $\beta$ as the probability that a manager who sees $i_{2} \neq i_{1}$ will choose to stick to her original plan, $s=a$. Thus, $\beta$ can be seen as a measure of announcement credibility. When commitment is not possible, we have $\beta=0$ (no credibility), while we have $\beta=1$ (full credibility) when there is full commitment. All other values of $\beta \in(0,1)$ represent different degrees of partial commitment. When the manager sees $i_{2}=i_{1}$, we assume that she chooses $s=a$ in period 2 . We formally prove this intuitive result later in Lemma 2.

The following proposition characterizes the partner's optimal decision in such a case.

Proposition 2. If $d=1$, the optimal strategy for the partner is

$$
\{x(a, d=1)=a, e(a, d=0)=e(\beta)\},
$$

where $e(\beta)$ is implicitly defined by $[p+(1-p) \beta] q^{\prime}(e)=1$.

Proof. When facing a degree of credibility $\beta$, the partner will choose his investment level in order to

$$
\max _{e \in[0,1]}[p+(1-p) \beta] q(e)-e .
$$

\footnotetext{
${ }^{8}$ For a critique of equilibrium selection procedures in cheap talk games, see Farrell and Rabin (1996).

${ }^{9} \mathrm{We}$ assume that committing to transfer decision-making power to the partner in the second period is not an option for the manager. Intuitively, transferring control over the choice of strategy to partners might have many unintended adverse consequences, which are not present in our model.
} 
Once again, under the assumptions on the function $q$, a unique solution for this problem exists. Also, the solution is interior and therefore characterized by

$$
[p+(1-p) \beta] q^{\prime}\left(e^{*}\right)=1
$$

The equality above implicitly defines the function $e(\beta):[0,1] \rightarrow[0,1]$ as the solution to the problem above for each possible $\beta$. Q.E.D.

Notice that, if the degree of commitment is $\beta=0$, the effort level with public announcements is the same as the one with only internal announcements: $e^{n}=e(0)$. Thus, we can use the function $e(\beta)$ to describe the partner's optimal behavior in all situations. The following lemma describes some properties of this function.

Lemma 1. Given the previous assumptions, the following results hold:

(i) $e^{\prime}(\beta)>0$.

(ii) $d e(\beta) / d p>0$ for $\beta \in[0,1)$.

(iii) $d e^{\prime}(\beta) / d p \leq 0$.

Proof. Let $f(e, \beta, p)=[p+(1-p) \beta] q^{\prime}(e)-1$. Parts (i) and (ii) follow directly from $\partial f / \partial \beta>0$ and $\partial f / \partial p>0$, while part (iii) follows from straightforward algebra. Q.E.D.

The first result in Lemma 1 is an important idea in this article. It says that partners' investments increase with the degree of commitment. In particular, it implies that disclosures of managers' private information, when minimally credible, increase partners' incentives to invest.

The second result is also very intuitive. It shows that announcements have value even if they are not credible; when the probability of the manager being right in period $1, p$, increases, the partner invests more. We note, however, that this effect is purely informational. The partner follows the manager's announcement in period 1 because he knows that the manager is better informed. Therefore, he is willing to invest more when the quality of the manager's information improves (i.e., $p$ increases). The third result implies that the informational effect of announcements is weaker the more committed the manager is. In particular, under full commitment, the partner knows that his project will be implemented whenever it is successful, thus the accuracy of the manager's information is irrelevant for his investment decision.

Expected profits. Let us consider the ex ante expected profits from the shareholders' standpoint. We assume that the identity of shareholders is irrelevant; therefore, in computing profits, we do not consider managerial shareholdings $\alpha$ as costs. We also assume that the benefits the partner receives if his project is implemented is not a cost for the firm. ${ }^{10}$

Ex ante expected profit for the firm as a function of $\beta$ is given by

$$
\Pi(\beta)=R+p q(\beta) h-(1-p) \beta R .
$$

The formula in (16) illustrates the tradeoff shareholders face. Credible announcements of managers' private information have benefits because they induce partners to invest more. The expression $p q(\beta) h$ represents the additional expected benefits from inducing partners to invest. Credible announcements also have costs. Managers ignore their unambiguous information $i_{2}$ in period 2, even when it contradicts their original signal $i_{1}$; thus, they sometimes make inefficient strategy implementation decisions. The term $(1-p) \beta R$ represents this cost.

From the shareholders' standpoint, the first-best strategy in the current environment requires the partner to undertake a large investment in period 1 and the manager to choose the right strategy in period $2\left(s=i_{2}\right)$. Given our assumptions, in general, the first best cannot be achieved, because

${ }^{10}$ Results are exactly identical if $\alpha$ is considered as a cost. Also, they are not significantly changed if the partner's benefit is considered as a cost, as long as the benefit from a successful project is assumed to be larger for the firm than for the partner, i.e., $h>1$. We choose the current approach for notational simplicity. 
that would imply sometimes paying partners even when their projects are not implemented. We thus focus on second-best solutions, the ones in which an optimal degree of commitment $\beta$ is chosen.

Define

$$
S B \equiv\{\beta \in[0,1]: \beta \in \underset{\beta}{\arg \max } \Pi(\beta)\} .
$$

The set $S B$ is nonempty because our assumptions ensure that $\Pi(\beta)$ is continuous. The secondbest levels of credibility could be anything from no credibility $(\beta=0)$ to full credibility $(\beta=1)$. Therefore, there is always a credibility level $\beta$ that maximizes ex ante profits. We now turn to the question of which levels of credibility can be sustained in equilibrium.

Internal announcements. We already have all the elements necessary to compute the equilibrium when the manager chooses not to disclose her information to the market $(d=0)$. In this case, the manager's internal announcement, $a$, is not credible and the partner chooses a low level of investment, $e^{n}$. The following proposition describes this case.

Proposition 3. If $d=0$, the unique perfect Bayesian equilibrium strategy profile is such that the manager chooses $\left\{a\left(i_{1}\right)=i_{1}, s\left(i_{1}, i_{2}\right)=i_{2}\right\}$ and the partner chooses $\{x(a, d=0)=a, e(a, d=$ $\left.0)=e^{n}\right\}$.

Proof. Notice first that, if the market has not observed $a$ (i.e., $d=0$ ), there is not enough information to separate types in equilibrium because knowledge of $s$ alone is not informative. Therefore, the market salary for managers, $w$, is the same for both types of managers.

We start by showing that $s=i_{2}$ is a strictly dominant strategy in period 2, if the manager follows $a\left(i_{1}\right)=i_{1}$ in period 1 , as long as we restrict the partner's strategy to the set $\{x(a)=a, e \in[0,1]\}$. In period 2, the manager learns $i_{2}$. Suppose that $i_{1}=i_{2}$. Therefore, choosing $s=i_{2}$ gives her an expected utility of

$$
U\left(s=i_{2} \mid i_{1}=i_{2}\right)=\alpha[q(e) h+R]+w .
$$

Choosing $s \neq i_{2}$ gives her

$$
U\left(s \neq i_{2} \mid i_{1}=i_{2}\right)=w .
$$

Clearly, the first term in (18) is positive, implying that $U\left(s=i_{2} \mid i_{1}=i_{2}\right)>U\left(s \neq i_{2} \mid i_{1}=i_{2}\right)$.

Suppose now that $i_{1} \neq i_{2}$. Therefore, choosing $s=i_{2}$ gives her an expected utility of

$$
U\left(s=i_{2} \mid i_{1} \neq i_{2}\right)=\alpha R+w .
$$

Choosing $s \neq i_{2}$ again gives her

$$
U\left(s \neq i_{2} \mid i_{1} \neq i_{2}\right)=w .
$$

Analogously, it follows that $U\left(s=i_{2} \mid i_{1} \neq i_{2}\right)>U\left(s \neq i_{2} \mid i_{1} \neq i_{2}\right)$. Therefore, choosing $s=i_{2}$ is a strictly dominant strategy in period 2 .

Going back one period, given that the partner chooses $x=a$ and that the manager wants to maximize the likelihood of getting $h$, it is optimal for her to report $a\left(i_{1}\right)=i_{1}$. From the partner's standpoint, given that the manager chooses $a=i_{1}$, the best predictor of $i_{2} i_{1} i_{1}$. Therefore, the partner chooses $x=a$.

The partner's choice of investment level will be given by

$$
p q^{\prime}\left(e^{n}\right)=1 \text {. }
$$

Therefore,

$$
\left\{a\left(i_{1}\right)=i_{1}, s\left(i_{1}, i_{2}\right)=i_{2} ; x(a, d=0)=a, e(a, d=0)=e^{n}\right\}
$$

is an equilibrium. It is straightforward to see that the equilibrium is unique. Q.E.D. 
This result shows that, when announcements are only internal, the manager always chooses $s=i_{2}$. Therefore, announcements are not credible. This does not mean that this equilibrium is necessarily suboptimal. Notice that the ex ante expected profit induced by this equilibrium is

$$
\Pi(0)=R+q(0) p h
$$

Therefore, if the second-best level of credibility is zero (i.e., $0 \in S B$ ), the equilibrium with only internal announcements, $d=0$, is optimal from the shareholders' perspective. However, if $0 \notin S B$, shareholders might prefer equilibria in which public announcements are made.

Public announcements. We now turn to the characterization of equilibria when managers disclose their views to outsiders $(d=1)$. In this case, the market for executives will use its knowledge about the manager's announcement $a$ to update its beliefs about managerial talent. We therefore start with a characterization of these beliefs.

In period 2, if $d=1$, the market can use its knowledge of $a$ and $s$ to update its beliefs about the quality of the manager. In this case, we denote the contingent salary in equilibrium by $w(s=a)$ when the manager chooses $s=a$ and by $w(s \neq a)$ when she chooses $s \neq a$.

In period 2, different signals rule out the possibility that a manager is a high-ability one, while identical signals increase the probability that she is a high-ability manager, i.e.,

$$
p\left(H \mid i_{1}=i_{2}\right)=\frac{\pi}{\pi+(1-\pi) p_{L}}>\pi .
$$

If the market could observe whether $i_{1}=i_{2}$ or $i_{1} \neq i_{2}$, it would offer salaries

$$
\begin{aligned}
& w\left(i_{1}=i_{2}\right) \equiv p\left(H \mid i_{1}=i_{2}\right) w_{H}+p\left(L \mid i_{1}=i_{2}\right) w_{L}, \\
& w\left(i_{1} \neq i_{2}\right) \equiv w_{L} .
\end{aligned}
$$

Thus, it follows that $w\left(i_{1}=i_{2}\right)>w\left(i_{1} \neq i_{2}\right)$.

We now analyze the equilibria of the continuation games starting in period 2 . Because the only relevant private information the manager has in the beginning of period 2 is whether $i_{1}=i_{2}$ or $i_{1} \neq i_{2}$, with a slight abuse of terminology, we will say that the manager is either of type $i_{1}=i_{2}$ or $i_{1} \neq i_{2}$. Her pure strategies in these games are either $s=a$ or $s \neq a$.

In order to restrict beliefs off the equilibrium path, we will sometimes impose either condition D1 in Cho and Kreps (1987) or Banks and Sobel's (1987) divinity requirement. These refinements play a role only for equilibrium candidates that, we believe, are clearly not reasonable.

The next result establishes that, in any equilibrium that satisfies the divinity requirement, managers always stick to their announcements when their first-period signal $i_{1}$ happens to be right:

Lemma 2. In any equilibrium that satisfies Banks and Sobel's divinity requirement in the continuation games starting at period 2, type $i_{1}=i_{2}$ will always play $s=a$.

Proof. See the Appendix.

This result is very intuitive; it simply says that a manager who gets it right in the first period will have no reason to change her mind.

The next result explains the reason why a manager who observes $i_{1} \neq i_{2}$ may still want to choose the "wrong" strategy $i_{1}$.

Lemma 3. In any equilibrium, $w(s=a)>w(s \neq a)$.

Proof. Since high-ability managers always receive a correct signal in period 1, Lemma 2 implies that they always play $s=a$. If type $i_{1} \neq i_{2}$ assigns a positive probability to playing $s \neq a$, we have that market beliefs $P(H \mid s=a)$ and $P(H \mid s \neq a)$ are given by

$$
P(H \mid s=a)=p\left(H \mid i_{1}=i_{2}\right) \cdot p\left(i_{1}=i_{2} \mid s=a\right)
$$

and

$$
P(H \mid s \neq a)=0 .
$$


In this case, the beliefs above are uniquely determined because $p\left(H \mid i_{1}=i_{2}\right)$ is given by (25) and $p\left(i_{1}=i_{2} \mid s=a\right)$ corresponds to the manager's strategy, which is known in equilibrium.

When the market observes managers choosing $s \neq a$ with a positive probability, it will offer the salaries

$$
w(s=a)=P(H \mid s=a) w_{H}+P(L \mid s=a) w_{L}
$$

and

$$
w(s \neq a)=w_{L} .
$$

Because $P(H \mid s=a)$ is positive, we have that, in this case, $w(s=a)>w(s \neq a)$.

When the market observes managers choosing $s \neq a$ with zero probability, there is a pooling equilibrium. In fact, from Lemma 2, this is the only candidate for a pooling equilibrium. In this case, once again, it must be that $w(s=a)>w(s \neq a)$ because, otherwise, type $i_{1} \neq i_{2}$ would prefer to switch to $s \neq a$. Q.E.D.

In the next proposition, we show that an equilibrium in the continuation games starting in period 2 always exists and is unique. We also provide a full characterization of the strategy profiles and beliefs that constitute the equilibrium for each subset of parameters. Before we do that, however, we explain the results heuristically.

Recall that $R$ is the certain firm revenue that the manager can secure if she chooses the right strategic direction and that $\alpha$ is the fraction of these benefits that accrue to her. Notice then that $\alpha R$ is the manager's temptation to renege on her announcement when $i_{1} \neq i_{2}$; by choosing the right direction, $s=i_{2}$, the manager gets $\alpha R$. However, a manager who observes $i_{1} \neq i_{2}$ will reveal her type by not following her initial plan and, therefore, will face a reduction in her salary in period 2 . Thus, a rational manager will weigh her temptation to renege against the potential loss in pay due to revealing her type to the managerial labor market. When the temptation to renege $\alpha R$ is sufficiently high relative to the salary loss from type revelation, only separating equilibria will exist, and announcements will not be credible. On the other hand, for low levels of $\alpha R$ relative to the salary loss from type revelation, only pooling equilibria will exist, and announcements will be credible.

Proposition 4. When the manager makes a public announcement $(d=1)$, a perfect Bayesian equilibrium for the game starting in period 2 always exists and is unique. Furthermore, the equilibrium is such that:

(i) If $\alpha R \in\left[w\left(i_{1}=i_{2}\right)-w_{L}, \infty\right)$, then the unique equilibrium implies full separation of types, such that strategies are $s\left(i_{1}=i_{2}\right)=a$ and $s\left(i_{1} \neq i_{2}\right) \neq a$ and market salaries are $w\left(i_{1}=i_{2}\right)$ for action $s=a$ and $w_{L}$ for action $s \neq a$ (beliefs are uniquely determined by Bayes's rule everywhere);

(ii) if $\alpha R \in\left(w-w_{L}, w\left(i_{i}=i_{2}\right)-w_{L}\right)$, then the unique equilibrium is a hybrid one in which type $i_{1}=i_{2}$ always chooses $s=a$ and type $i_{1} \neq i_{2}$ chooses $s=a$ with probability $\beta^{\prime} \in(0,1)$ and $s \neq a$ with probability $1-\beta^{\prime}$, where $\beta^{\prime}=$ $[p /(1-p)]\left[\left(w\left(i_{1}=i_{2}\right)-w_{L}\right) / \alpha R-1\right]$, and market salaries are $w_{M}(s=a)=\alpha R+w_{L}$ for action $s=a$ and $w_{L}$ for action $s \neq a$ (beliefs are uniquely determined by Bayes's rule everywhere); and

(iii) if $\alpha R \in\left(0, w-w_{L}\right]$, then the unique equilibrium implies pooling of types, such that strategies are $s\left(i_{1}=i_{2}\right)=s\left(i_{1} \neq i_{2}\right)=a$ and market salaries are $w$ for action $s=a$ and $w_{L}$ for action $s \neq a$ (off the equilibrium path, the market believes that the manager is of type $i_{1} \neq i_{2}$ with probability 1$)$.

Proof. See the Appendix.

We have defined $\beta$ as a measure of announcement credibility. Proposition 4 implies that $\beta=0$ in case 1 (no credibility), $\beta=\beta^{\prime}$ in case 2 (partial credibility), and $\beta=1$ in case 3 (full credibility). 
Some simple comparative statisics follow directly from this proposition. Announcements are more likely to be credible when managerial talent is more important. To see this, consider a mean-preserving spread in the salary distribution, i.e., let $w_{H}$ go up and $w_{L}$ go down in a manner that keeps $w$ constant. The salary gap in period $2, w\left(i_{1}=i_{2}\right)-w_{L}$, will go up, implying that the intervals in cases 2 and 3 will both increase. In such a case, there will be more parameter values for which announcements are at least partially credible.

Corollary 1. Public announcements are more likely to be credible when the managerial skill premium $w_{H}-w_{L}$ is high.

It is also straightforward to see that increases in $\alpha R$ will reduce the credibility of public announcements.

The information disclosure decision. The uniqueness of the solution of the game in period 2 guarantees that $\beta$ is unique. Fully rational players will correctly anticipate $\beta$ when making their first-period decisions. Therefore, when facing a credibility degree of $\beta$, the partner will choose $e(\beta)$. We define the set

$$
\Omega \equiv\{\beta \in[0,1] \mid \Pi(\beta)>\Pi(0)\} .
$$

The next proposition completes the full characterization of the solution of the model. We make the simplifying assumption that, when the manager is indifferent between disclosing her information or not, she will choose $d=0$. We show that the manager chooses to make a public announcement if and only if it increases profits.

Proposition 5. $d=1$ if and only if $\beta \in \Omega$.

Proof. The crucial part of the proof is to recognize that, regardless of the value of $\beta$, the manager never expects to increase her salary by choosing $d=1$.

To see this, notice that the expected salary in a pooling equilibrium is $w$, while the expected salary in a separating equilibrium is

$$
\begin{aligned}
p w(s & =a)+(1-p) w(s \neq a) \\
& =p\left[p\left(H \mid i_{1}=i_{2}\right) w_{H}+p\left(L \mid i_{1}=i_{2}\right) w_{L}\right]+(1-p)\left[p\left(H \mid i_{1} \neq i_{2}\right) w_{H}+p\left(L \mid i_{1} \neq i_{2}\right) w_{L}\right] \\
& =p\left[\frac{\pi}{p} w_{H}+\frac{(1-\pi) p_{L}}{p} w_{L}\right]+(1-p) w_{L} \\
& =\pi w_{H}+(1-\pi) w_{L}=w .
\end{aligned}
$$

Similar algebra implies that the expected salary in a hybrid equilibrium is also $w$.

Therefore, the choice between $d=1$ and $d=0$ can affect only profits. For a given $\beta$, the manager's expected payoff from choosing $d=0$ is

$$
\alpha\{R+q(0) p h\}+w=\alpha \Pi(0)+w,
$$

while her expected payoff from choosing $d=1$ is

$$
\alpha\{R+q(\beta) p h-(1-p) \beta R\}+w=\alpha \Pi(\beta)+w .
$$

Therefore, a necessary and sufficient condition for the manager to choose $d=1$ (recall that ties are broken in favor of $d=0)$ is that $\Pi(\beta)>\Pi(0)$ or, equivalently, $\beta \in \Omega$. Q.E.D.

We have now fully described the equilibrium play. For any given set of parameters, Proposition 4 fully characterizes the unique equilibrium of the continuation game starting in period 2. It also determines a unique $\beta$. The partner can then compute his desired level of investment $e(\beta)$ conditional on observing $d=1$. If he observes $d=0$, he rationally chooses $e(0)$. With knowledge of $e(\beta)$ and $e(0)$, the manager constructs the set $\Omega$. If $\beta \in \Omega$, the manager chooses $d=1$, and if $\beta \notin \Omega$, she chooses $d=0$. 
Welfare analysis (using shareholder value as the metric) implies that whenever managers care about their opportunities outside the firm, shareholders are never worse off. It is clear that managers will choose to disclose their private information only when it increases the firm's value above the default profit $\Pi(0)$. Thus, voluntary public announcements are always value enhancing. It should be noted, however, that this conclusion depends on the assumption that managers initially do not know their types. If they do, their disclosure decisions will also be influenced by signalling considerations.

In our model, public announcements are not motivated by the will of a good manager to separate herself from a bad one. The decision of whether or not to disclose business strategy information is taken before a manager has any information to update her beliefs about her own ability. In fact, while there are equilibria in which managers disclose their private information to outsiders, there are no equilibria in which good managers are separated from bad ones. What makes a manager willing to disclose information is the return gained from motivating partners. Moreover, what makes partners confident to invest in the announced strategic direction is their belief that, even if the manager later realizes that the original direction was not the best, she will stick to it because of concerns about her reputation.

We are now able to characterize the equilibrium consequences of the tradeoff faced by the manager. Disclosure of information is more valuable the more valuable partners' ex ante investments are (e.g., the relative importance of partners' ideas or skills). Disclosure of information is less valuable the more value is added by managers who make decisions that are ex post efficient (e.g., to scrap a bad project). In our model, $h$ is a measure of the value of ex ante efficient actions and $R$ is a measure of the value of ex post efficient actions. A result that follows directly from our characterization of the equilibrium is as follows.

Corollary 2. Managers are more likely to disclose their private information about strategy in firms where the output from strategy-specific investments $(h)$ is high and where the value of making correct decisions about strategy $(R)$ is low.

This corollary is our answer to the last question advanced in the introduction: When should we expect to see voluntary disclosures of information about corporate strategy? We conclude that we should expect to encounter variation in disclosure practices across firms with different characteristics. The empirical relevance of Corollary 2 depends on one's ability to find good empirical proxies for $h$ and $R .^{11}$

\section{Managerial compensation and performance}

- We have assumed a fixed level of managerial shareholdings, $\alpha$. It is easy to rewrite the model so that $\alpha$ is chosen in order to maximize firm value. For the sake of brevity, we will not pursue this simple extension here, but we want to report its main conclusions.

There are three main conclusions from such an extension: (1) In general, there is a tradeoff concerning granting shares to managers. Because more shares make managers more eager to change strategies in period 2, managerial ownership mitigates the problem of making inefficient strategy implementation decisions. However, it also reduces partners' incentives to undertake strategy-specific investments. (2) Optimal compensation design for managers increases profits and also guarantees that the second-best outcome will be achieved. (3) Finally, none of the insights obtained from the model developed in Section 3 depend on the assumption of exogenous managerial shareholdings.

Another crucial assumption we have made concerning managerial compensation is that the market for executives pays fixed salaries to the managers. That is, we have assumed that salaries may depend on anything that the market has observed, but they cannot depend on the final revenue of the firm, $r$. However, it can be shown that, if the market can offer compensation to managers

${ }^{11}$ Other parameters also affect the likelihood of public announcements. For example, we have shown that increases in $w_{H}-w_{L}$ increase the credibility of public announcements. Thus, these parameters are also useful in potential empirical explorations of our results. 
that is contingent on $r$, public announcements will never be credible and our model thus becomes uninteresting. Therefore, it is important to explain why we rule out this type of contract.

An optimal compensation contract should give some weight to previously observed actions taken by the manager as well as to the performance of her firm. However, because in our model the true state of nature is fully revealed ex post, future performance together with past behavior are fully informative about the manager's private information. Thus, pooling equilibria can never occur. However, we have assumed full revelation of the true state only for simplicity, not for realism. In reality, future performance can be used to infer some, but not all, of the manager's private information. In order for the qualitative results of our model to hold, the only assumption we need is that knowledge of future performance and past behavior should not be sufficient to always fully separate types in equilibrium. Thus, here we show that our model is indeed robust to the case where the market offers compensation contingent on performance, as long as performance does not fully reveal the true state of nature.

Consider the following simple variation of our model. Suppose that, when $s=i_{2}$, firm revenue is $R$ with probability $\eta$ and 0 with probability $1-\eta$. That is, our original model is just a special case of this one, in which $\eta=1$. We slightly modify the timing: we let the manager's salary be determined after output $(r)$ is realized. Now, even if the market could use the final output to assess the manager's ability, the market is still unable to always separate types in equilibrium, implying that not only final performance, but also the manager's actions (the disclosure and strategy decisions), will affect the manager's salary in period 2.

In order to see this, consider a manager who had publicly announced $a$ in period 1 and now observes $i_{2} \neq a$. If she chooses $s \neq a$, the market will know for sure that she is of the low type and will pay her $w_{L}$. If she chooses $s=a$, firm value will be zero with probability 1 and, from (29), the market will pay her a salary of

$$
w(s=a, r=0)=\frac{\pi(1-\eta) w_{H}+(1-\pi)\left[\left(1-p_{L}\right)+p_{L}(1-\eta)\right] w_{L}}{\pi(1-\eta)+(1-\pi)\left[\left(1-p_{L}\right)+p_{L}(1-\eta)\right]},
$$

assuming that we are in an equilibrium in which type $i_{2} \neq a$ chooses $s=a$. Clearly, $w(s=a, r=0)>w_{L}$ except for $\eta=1$, where $w(s=a, r=0)=w_{L}$. Thus, as long as firm performance is not fully informative about managerial talent $(\eta<1)$, full separation of types will not be accomplished by offering pay contingent on future performance. Thus, the qualitative results of our model are unaffected.

Equation (35) has other interesting implications. Because $w(s=a, r=0)$ is decreasing in $\eta$, as performance becomes more informative about the true state of nature (as $\eta$ increases), incentives to commit decrease for two reasons: (1) the gain from committing to $s=a$ when $i_{2} \neq a$, $w(s=a, r=0)-w_{L}$, decreases with $\eta$ and (2) the cost of deviating from the right strategy, $\eta \alpha R$, increases with $\eta$.

We can interpret $\eta$ as a measure of strategic clarity: when $\eta=1$, it is ex post perfectly clear which strategy was the right one. We conclude that strategic clarity is bad for commitment. In order for managers to have incentives to commit, there must be at least some ambiguity ex post concerning the optimality of managers' decisions. This is indeed a very intuitive result. In the original version of our model, this ambiguity was achieved through the assumption that salaries were determined before output was realized in the end of the game. Here we have shown that this assumption is not necessary: as long as there is some ambiguity left at the end of the game, commitment is still possible.

\section{Empirical implications}

There are a number of new empirical implications of our model that could serve as guides for future empirical explorations of firms' disclosure behavior. Here we briefly discuss some of them.

The main new results from our model are twofold. Voluntary disclosures of information about corporate strategy are more likely to occur when: (1) managerial career concerns are important 
and (2) the value of ex ante specific investment is high vis-à-vis the value of ex post flexibility in strategy choice.

The first result implies a positive correlation between the disclosure decision and proxies for career concerns. Quantitative measures of disclosure of information about strategy are not difficult to construct and they have been used in previous works (see Amir and Lev, 1996; Narayanan et al., 2000). Top executives' career concerns can be proxied by age or time to retirement (Gibbons and Murphy, 1992), by how visible the performance of their firms are (Fee and Hadlock, 2003) or by measures of competition in the managerial labor market.

The second result suggests that disclosures of information about corporate strategies are more likely to occur in industries or firms where strategy-specific investments are more important. For example, in firms where workers are required to acquire a very peculiar combination of skills (see Lazear, 2003, for some examples), public disclosure of strategy information is likely to occur more often. On the other hand, in firms where the value of strategic flexibility ex post is very high, maybe due to a highly unpredictable environment, strategy disclosure should be less common.

We are unaware of any empirical studies testing these implications. We hope that our model can provide an additional motivation to such attempts.

Our model does not have any direct implication for the relationship between firm value and the decision to disclose information about strategy. This is because disclosure has both costs and benefits; thus, one should observe variation in disclosure decisions across firms with different characteristics if these firms are maximizing their market values. There is some empirical work suggesting that voluntary disclosure of qualitative information is value enhancing (Amir and Lev, 1996; Narayanan et al., 2000). This result is compatible with our model if one adds a tendency to underdisclose information. For example, in our model, if managers are risk averse, they will often prefer not to disclose their information because that will increase the variability in their salaries in period 2.

Finally, Cools and van Praag (2003) provide evidence that the disclosure of information about the internal use of a corporate target has additional positive effects on a firm's value that go beyond the value of internally using that corporate target. This finding is broadly consistent with the theory we develop in this article.

\section{Final remarks}

- We have shown three main results in this article: (1) Managers will voluntarily disclose their private information about corporate strategy to partners because they want to induce partners to undertake investments that are specific to certain strategic directions; (2) managerial public announcements of information about strategy are credible because managers are concerned about their reputations; and thus, (3) voluntary public disclosures of information about corporate strategy can be value enhancing due to their positive effects on partners' incentives.

Our model provides a framework for understanding the costs and benefits of nonfinancial disclosure. Previous empirical works have focused primarily on the potential benefits of nonfinancial disclosure (Amir and Lev, 1996; Narayanan et al., 2000). Given the predominance of financial reporting by corporations, some have suggested that "non-financial disclosure in annual reports needs improvement" (Patel and Dallas, 2002, p. 4). Our trade-off view of the disclosure decision does not support mandatory disclosure provisions. By disclosing their intentions, managers will be reluctant to change their minds in the future, which may lead them to make inefficient project implementation decisions. When this distortion is sufficiently large, managers will choose not to disclose information. Thus, although the equilibrium outcome may be suboptimal, shareholders many times benefit from managers' discretion with respect to disclosure decisions.

\section{Appendix}

- Proofs of Lemma 2 and Proposition 4 follow.

Proof of Lemma 2. Suppose there is a pooling equilibrium in which both types play $s \neq a$. The equilibrium salary on the equilibrium path should be $w$ and the off-the-equilibrium-path salary $w(s=a)$ should be strictly less than $w$; otherwise,

(C) RAND 2007. 
type $i_{1}=i_{2}$ would surely want to deviate. This last requirement implies that the market's beliefs should be such that, in case it observes a deviation, it attributes a probability higher than $(1-\pi)$ to a scenario where type $i_{1} \neq i_{2}$ is the one deviating from equilibrium play. However, for all beliefs and equilibrium best-response actions chosen by the market that would make type $i_{1} \neq i_{2}$ willing to deviate, type $i_{1}=i_{2}$ would also want to deviate. Therefore, the divinity criterion of Banks and Sobel (1987) requires that the market's belief that the type $i_{1} \neq i_{2}$ was the one deviating to be no greater than $1-\pi$. But this restriction on beliefs eliminates all pooling equilibria in which $w(s=a)<w$; therefore, there is no equilibrium in which both types play $s \neq a$. In a fully separating equilibrium, if $i_{1}=i_{2}$ chooses $s \neq a, i_{1} \neq i_{2}$ will also want to choose $s \neq a$, but then this will not be a separating equilibrium. In a hybrid equilibrium, type $i_{1}=i_{2}$ will only randomize between $s \neq a$ and $s=a$ if she is indifferent between the two. This implies $w(s=a)<w(s \neq a)$. But then type $i_{1} \neq i_{2}$ will always choose $s \neq a$; thus, Bayesian updating implies $w(s=a)>w(s \neq a)$, which is a contradiction. Q.E.D.

Proof of Proposition 4. We will first establish some results and define some notation.

Let us suppose that a separating equilibrium exists. Lemma 2 implies that types $i_{1}=i_{2}$ and $i_{1} \neq i_{2}$ must assign probability 1 to $s=a$ and $s \neq a$, respectively. Therefore, market beliefs obey (27) and (28), and then $w(s \neq a)$ is given by (30), while (29) specializes to

$$
w_{S}(s=a)=w\left(i_{1}=i_{2}\right) \equiv p\left(H \mid i_{1}=i_{2}\right) w_{H}+p\left(L \mid i_{1}=i_{2}\right) w_{L} .
$$

Therefore, beliefs and salaries are uniquely defined in a separating equilibrium.

Suppose that, in period 2, the manager is of type $i_{1} \neq i_{2}$. If the manager chooses $s \neq a$, we define her utility in the beginning of period 2 as

$$
V_{S}\left(s \neq a \mid i_{1} \neq i_{2}\right)=\alpha R+w_{L}
$$

However, if she chooses $s=a$, her utility is

$$
V_{S}\left(s=a \mid i_{1} \neq i_{2}\right)=w\left(i_{1}=i_{2}\right) .
$$

Therefore, the following lemma is straightforward:

Lemma A1. A necessary and sufficient condition for a separating equilibrium to exist is that

$$
\alpha R \geq w\left(i_{1}=i_{2}\right)-w_{L} .
$$

The sufficiency of this condition for the existence of a separating equilibrium follows immediately from the fact that, whenever type $i_{1} \neq i_{2}$ does not have incentives to deviate from a separating equilibrium, type $i_{1}=i_{2}$ has even fewer incentives to deviate. This separating equilibrium is unique among the class of separating equilibria due to Lemma 2 . This proves part 1.

Suppose now we are in a pooling equilibrium. Lemma 2 implies that both types choose $s=a$, implying that market beliefs obey (27) only. Equation (29) specializes to

$$
w_{P}(s=a)=\pi w_{H}+(1-\pi) w_{L}=w .
$$

In a pooling equilibrium, if a manager of type $i_{1} \neq i_{2}$ chooses $s \neq a$, her utility is

$$
V_{P}\left(s \neq a \mid i_{1} \neq i_{2}\right)=\alpha R+w_{P}(s \neq a)
$$

However, if she chooses $s=a$, it is

$$
V_{P}(s=a \mid i \neq n)=w .
$$

Thus, if type $i_{1}=i_{2}$ finds it profitable to deviate, type $i_{1} \neq i_{2}$ would also find it profitable to deviate. Cho and Kreps's (1987) $\mathrm{D} 1$ criterion implies that the market should think that type $i_{1} \neq i_{2}$ is infinitely more likely to deviate than $i_{1}=i_{2}$ in a pooling equilibrium, implying that

$$
w_{P}(s \neq a)=w_{L}
$$

Therefore, the following lemma is straightforward:

Lemma A2. A necessary and sufficient condition for a pooling equilibrium to exist is that

$$
\alpha R \leq w-w_{L}
$$

The sufficiency of this condition for the existence of a pooling equilibrium again follows from the fact that, whenever 
type $i_{1} \neq i_{2}$ does not have incentives to deviate from a pooling equilibrium, type $i_{1}=i_{2}$ has even fewer incentives to deviate. This pooling equilibrium is unique among the class of pooling equilibria due to Lemma 2 and to the fact that imposing Cho and Kreps's D1 refinement completely pins down beliefs off the equilibrium path. This proves part (iii).

Consider now the possibility of a hybrid equilibrium. Lemma 2 implies that only those managers who observe $i_{1} \neq i_{2}$ may randomize. Because the $i_{1} \neq i_{2}$ type (and only this type) chooses $s \neq a$ with positive probability, it follows that the salary in this case should be the same as in a separating equilibrium, that is, $w_{M}(s \neq a)=w_{S}(s \neq a)=w_{L}$. If a manager of type $i_{1} \neq i_{2}$ chooses $s \neq a$, her expected utility in the beginning of period 2 is

$$
V_{M}\left(s \neq a \mid i_{1} \neq i_{2}\right)=\alpha R+w_{L}
$$

However, if she chooses $s=a$, it is

$$
V_{M}\left(s=a \mid i_{1} \neq i_{2}\right)=w_{M}(s=a) .
$$

Given that the manager should be indifferent between the two actions, we have that

$$
w_{M}(s=a)=\alpha R+w_{L} .
$$

Let $\beta^{\prime}$ be the proportion of type $i_{1} \neq i_{2}$ that chooses $s=a$. In game-theoretic jargon, $\beta^{\prime}$ is the action prescribed by her behavior strategy when she learns that her type is $i_{1} \neq i_{2}$. Because $\beta^{\prime}<1$ (otherwise, we are in a pooling equilibrium), the market salary for managers who choose $s=a$ should be strictly higher than $w$ because there is a positive probability that a type $i_{1} \neq i_{2}$ will not choose $s=a$. Thus, a necessary condition for a strictly hybrid equilibrium to exist is that

$$
w_{M}(s=a)>w .
$$

From condition (A12), this implies

$$
\alpha R+w_{L}>w .
$$

Note also that Bayesian updating implies that

$$
w_{M}(s=a)=\frac{p}{p+(1-p) \beta^{\prime}} w\left(i_{1}=i_{2}\right)+\frac{(1-p) \beta^{\prime}}{p+(1-p) \beta^{\prime}} w_{L} .
$$

Conditions (A12) and (A15) together imply

$$
\beta^{\prime}=\frac{p}{1-p}\left[\frac{w\left(i_{1}=i_{2}\right)-w_{L}}{\alpha R}-1\right] .
$$

Because $\beta^{\prime}>0$ in a hybrid equilibrium, we have that a necessary condition for a hybrid equilibrium to exist is

$$
\alpha R<w\left(i_{1}=i_{2}\right)-w_{L}
$$

Thus, conditions (A14) and (A17) imply the necessity part of the following lemma.

Lemma A3. A necessary and sufficient condition for a hybrid equilibrium to exist is that

$$
\alpha R>w-w_{L}
$$

and

$$
\alpha R<w\left(i_{1}=i_{2}\right)-w_{L}
$$

To prove sufficiency, we need to show that the two conditions above imply the existence of a $\beta^{\prime} \in(0,1)$. Notice that condition (A16) defines a unique $\beta^{\prime}$. If condition (A19) holds, one can see from (A16) that this $\beta^{\prime}$ will always be strictly greater than zero.

From (A16), we have that the following condition is necessary and sufficient for $\beta^{\prime}$ to be strictly less than 1 :

$$
\alpha R>p\left[w\left(i_{1}=i_{2}\right)-w_{L}\right]
$$

Using the fact that

$$
w=p w\left(i_{1}=i_{2}\right)+(1-p) w_{L},
$$

we conclude that

$$
w-w_{L}=p\left[w\left(i_{1}=i_{2}\right)-w_{L}\right]
$$

which implies that condition (A18) is equivalent to condition (A20). This completes the proof.

(c) RAND 2007 
Again, this hybrid equilibrium is unique among the class of hybrid equilibria, as one can see from equation (A16). This proves part (ii).

We note that the three intervals for $\alpha R$ described by the lemmas above are disjoint; therefore, there is no case in which more than one type of equilibrium exists. Because the equilibrium is unique in each interval, there is at most one equilibrium for the game. Because the union of the three intervals is equal to $(0, \infty)$, an equilibrium always exists. Q.E.D.

\section{References}

Amir, E. AND Lev, B. "Value-Relevance of Nonfinancial Information: The Wireless Communication Industry." Journal of Accounting and Economics, Vol. 22 (1996), pp. 3-30.

BAnKs, J.S. ANd Sobel, J. “Equilibrium Selection in Signaling Games.” Econometrica, Vol. 55 (1987), pp. 647-661.

Bоoт, A.W.A. "Why Hang on to Losers? Divestitures and Takeovers." Journal of Finance, Vol. 47 (1992), pp. 1401-1423.

- And Thakor, A.V. "The Many Faces of Information Disclosure.” Review of Financial Studies, Vol. 14 (2001), pp. 1021-1057.

Botosan, C.A. "Disclosure Level and the Cost of Equity Capital." Accounting Review, Vol. 72 (1997), pp. 323-349.

Brandenburger, A. and Polak, B. "When Managers Cover Their Posteriors: Making the Decisions the Market Wants to See." RAND Journal of Economics, Vol. 27 (1996), pp. 523-541.

Cho, I.-K. And Kreps, D.M. "Signaling Games and Stable Equilibria.” Quarterly Journal of Economics, Vol. 102 (1987), pp. 179-222.

Cools, K. and van PraAg, C.M. “The Value Relevance of Disclosing a Single Corporate Target.” Working Paper, Tinbergen Institute, 2003.

Crawford, V.P. ANd Sobel, J. “Strategic Information Transmission.” Econometrica, Vol. 50 (1982), pp. 1431-1451.

Diamond, D.W. “Optimal Release of Information by Firms.” Journal of Finance, Vol. 60 (1985), pp. 1071-1094.

- AND VerrecCHIA, R.E. "Disclosure, Liquidity, and the Cost of Capital." Journal of Finance, Vol. 66 (1991), pp. 1325-1359.

Farrell, J. And Rabin, M. “Cheap Talk.” Journal of Economic Perspectives, Vol. 10 (1996), pp. 103-118.

Fee, C.E. And Hadlock, C.J. "Raids, Rewards, and Reputations in the Market for Managerial Talent." Review of Financial Studies, Vol. 16 (2003), pp. 1315-1357.

Gibbons, R. And MurPhy, K.J. "Optimal Incentive Contracts in the Presence of Career Concerns: Theory and Evidence." Journal of Political Economy, Vol. 100 (1992), pp. 468-505.

Hart, O. and Holmström, B. “A Theory of Firm Scope.” Working Paper, Harvard and MIT, 2002.

Healy, P.M. and PalePU, K.G. "Information Asymmetry, Corporate Disclosure, and the Capital Markets: A Review of the Empirical Disclosure Literature." Journal of Accounting and Economics, Vol. 31 (2001), pp. 405-440.

Holmström, B. “Managerial Incentive Problems: A Dynamic Perspective.” Review of Economic Studies, Vol. 66 (1999), pp. 169-182.

Kanodia, C., Bushman, R., And Dickhaut, J. "Escalation Errors and the Sunk Cost Effect: An Explanation Based on Reputation and Information Asymmetries.” Journal of Accounting Research, Vol. 27 (1989), pp. 59-77.

Lazear, E.P. “Firm-Specific Human Capital: A Skill-Weights Approach.” NBER Working Paper no. 9679, 2003.

Narayanan, V.K., Pinches, G.E., Kelm, K.M., and Lander, D.M. "The Influence of Voluntarily Disclosed Qualitative Information.” Strategic Management Journal, Vol. 21 (2000), pp. 707-722.

Patel, S.A. AND Dallas, G. "Transparency and Disclosure: Overview of Methodology and Study Results-United States." Standard \& Poor's document, 2002.

Prendergast, C. And Stole, L. "Impetuous Youngsters and Jaded Old-Timers: Acquiring a Reputation for Learning." Journal of Political Economy, Vol. 104 (1996), pp. 1105-1134.

Rotemberg, J.J. and SAloner, G. "Visionaries, Managers and Strategic Direction." RAND Journal of Economics, Vol. 31 (2000), pp. 693-716.

Scharfstein, D.S. and Stein, J.C. "Herd Behavior and Investment." American Economic Review, Vol. 80 (1990), pp. $465-479$.

Stocken, P.C. "Credibility of Voluntary Disclosure.” RAND Journal of Economics, Vol. 31 (2000), pp. 359-374.

VAN DEN SteEn, E. “Organizational Beliefs and Managerial Vision.” Journal of Law, Economics, and Organization, Vol. 21 (2005), pp. 256-283.

Zwiebel, J. “Corporate Conservatism and Relative Compensation.” Journal of Political Economy, Vol. 103 (1995), pp. $1-25$. 